\title{
DNA Repair Gene Polymorphisms Do Not Predict Response to Radiotherapy-Based Multimodality Treatment of Patients with Rectal Cancer: a Meta-analysis
}

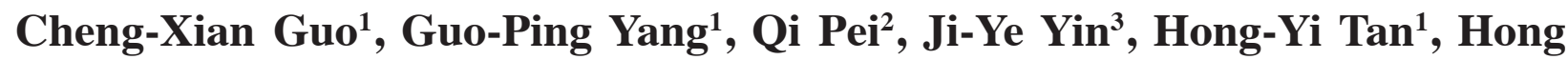 \\ Yuan ${ }^{1 *}$
}

\begin{abstract}
Background: : A number of association studies have been carried out to investigate the relationship between genetic polymorphisms in DNA repair genes and response to radiotherapy-based multimodality treatment of patients with rectal cancer. However, their conclusions were inconsistent. The objective of the present study was to assess the role of DNA repair gene genetic polymorphisms in predicting genetic biomarkers of the response in rectal cancer patients treated with neoadjuvant chemoradiation. Materials and Methods: Studies were retrieved by searching the PubMed database, Cochrane Library, Embase, and ISI Web of Knowledge. We conducted a meta-analysis to evaluate the association between genetic polymorphisms and the response in rectal cancer treated with neoadjuvant chemoradiation by checking odds ratios (ORs) and $95 \%$ confidence intervals (CIs). Results: Data were extracted from 5 clinical studies for this meta-analysis. The results showed that XRCC1 RS25487, XRCC1 RS179978, XRCC3 RS861539, ERCC1 RS11615 and ERCC2 RS13181 were not associated with the response in the radiotherapy-based multimodality treatment of patients with rectal cancer $(p>0.05)$. Conclusions: This study shows that DNA repair gene common genetic polymorphisms are not significantly correlated with the radiotherapy-based multimodality treatment in rectal cancer patients.
\end{abstract}

Keywords: DNA repair genes-genetic polymorphism-response-rectal cancer-meta-analysis

Asian Pac J Cancer Prev, 16 (2), 713-718

\section{Introduction}

In recent 10 years, the incidence of rectal cancer is rise on the trend (Jemal et al., 2010). Rectal cancer represents a common and severe gastrointestinal illness, which has the high risk of locoregional recurrence and the development of distant metastasis (Lamas et al., 2012). Surgery remains the bulwarks of treatment for rectal cancer throughout the world(Rajput and Bullard Dunn, 2007). But the overall 5-year survival rate hovers around 50\% (Kockerling et al., 1998). The local recurrence of rectal cancer is the main reason for the failure of rectal cancer treatment (Rodel et al., 2005; Vecchio et al., 2005). With the equipment of radiotherapy update, the development of the radiation technology and the radiation biology was rapid(Camma et al., 2000). The latter plays an important role as more than half of the cancer patients with radiotherapy (Borchiellini et al., 2012; Kerns et al., 2014). Recent studies paid more attention to combine with surgery, radiotherapy, and chemotherapy for the treatments of rectal cancer (Roh et al., 2009). Radiotherapy is an important means of adjuvant therapy for rectal cancer and also important means of palliative care for advanced rectal cancer (Kapiteijn et al., 2001). Radiotherapy can reduce the risk of local recurrence of postoperative rectal cancer (Bouzourene et al., 2002). Preoperative radiotherapy is superior to the postoperative radiotherapy (Sauer et al., 2004). With the wide application of radiotherapy in rectal cancer, more and more studies have found clinical efficacy and adverse effects of radiotherapy showed significant individual difference(Read et al., 2001).

Although the detail mechanisms for individual difference in radiotherapy remained unknown, genetic polymorphisms were demonstrated to be one of the major factors influencing the radiotherapy, especially the genetic polymorphisms of DNA repair genes (Gordon et al., 2006; Terrazzino et al., 2006). DNA damage response plays a significant role in the biological effects of radiotherapy. A major part of cellular damage to radiotherapy is related to direct DNA damage. Therefore, DNA repair genes with functional mutations may affect the sensitivity of irradiation, which affects the effect and toxicity of radiotherapy. If the gene mutation associated with poor DNA-repair ability, which should lead to increased sensitivity to irradiation, and may be increase radiotherapy efficacy, even though could be induced radiotherapy

${ }^{1}$ Center of Clinical Pharmacology, the Third Xiangya Hospital, ${ }^{2}$ Department of Pharmacy, the Third Xiangya Hospital, Central South University, Changsha, China; 3Institute of Clinical Pharmacology, Central South University, Changsha, China *For correspondence: yuanhongxy3@163.com 
toxicity. Several studies assessed the impact of DNA repair gene polymorphisms on radiotherapy efficacy, especially XRCC-family genes (XRCC1 and XRCC3) and ERCCfamily genes (ERCC1 and ERCC2) polymorphisms (Balboa et al., 2010). Although there are many studies reported that XRCC1, XRCC3, ERCC1 and ERCC2 genes common polymorphisms influence on individual differences of therapeutic efficacy of radiotherapy for rectal cancer, but the results are often not unified (Balboa et al., 2010; Lamas et al., 2012). For example, Lamas et al. found X-ray-repair-cross complementing 1 (XRCC1) rs25487 was significantly associated with the response of radiotherapy in rectal cancer while other studies presented not consistent (Balboa et al., 2010; Cecchin et al., 2010; Grimminger et al., 2010; Lamas et al., 2012). One important reason might be the small number of patients.

The aim of this study is to provide a comprehensive assessment on the association between DNA repair genes (XRCC1, XRCC3, ERCC1 and ERCC2) genetic polymorphisms and the response of radiotherapy in rectal cancer. We collected all available publications on pharmacogenetic studies of radiotherapy-based multimodality treatment in rectal cancer, and quantitatively studied them using meta-analysis.

\section{Materials and Methods}

\section{Literature search}

Published articles were searched in four electronic databases included PubMed database, Cochrane Library, Embase, and ISI Web of Knowledge, screening all available information from the first available article to May 2014. Publications were retrieved using keywords included "radiotherapy" or "radiation therapy" or "irradiation", and "polymorphism" or "SNP" or "single nucleotide polymorphism" or "mutation" or "variation", and "rectal cancer" or "rectal carcinoma". The search was ascertained for only English language publications and was performed independently by two authors (G.C.X. and Y.G.P.). The identified articles were reviewed carefully and the differences between searchers were discussed and solved with consensus.

\section{Publication selection criteria}

Publications were prescreened and studies were included if they met the following applies:(a) patients with "rectal cancer" or "rectal carcinoma"; (b) trials had the radiotherapy-based multimodality treatment; (c) the data of TRG stratified by polymorphisms could be obtained from the original article or author. Studies were excluded if any of the following criteria: (a) the data of TRG reported in the paper was not specific to polymorphism or could not be attributed to a specific polymorphism; (b) repeated publications, abstracts, letters, or review articles.

\section{Data extraction}

Data was carefully extracted from all eligible papers independently by two authors (G.C.X. and Q.P.). The standardized form was used for each of the included studies, in which following information was collected: first author's name, publication year, ethnicity (country), total number of patients included in the study, treatment regimens, polymorphisms, and dbSNP number of investigated polymorphisms, genotyping methods, disease stage, and the number of TRG in different genotypes. Any discrepancies between extractors were discussed and solved with consensus.

\section{Data analysis}

Revman 5 was used to analyze data. A meta-analysis was conducted using a random effects model or fixed effects model of genetic polymorphisms and TRG in rectal cancer with the radiotherapy-based multimodality treatment. In the study, TRG grades were defined as following, grade 1: the absence of residual cancer; grade 2: the presence of rare residual cancer cells; grade 3: an increase in the number of residual cancer cells but with fibrosis predominating; grade 4: residual cancer outgrowing fibrosis; and grade 5: the absence of regressive changes(Mandard et al., 1994). Patients were subdivided into two groups: the responders (TRG1 and TRG2) and the non-responders (TRG3, TRG4, andTRG5) (Mandard et al., 1994; Vecchio et al., 2005).

We evaluated the influence of theXRCC1 (rs25487 and XRCC1 rs1799782), XRCC3 (rs861539), ERCC1 (rs11615), and ERCC2 (rs13181) variant on responders in rectal cancer with the radiotherapy-based multimodality treatment. The pooled odds ratio (OR) and associated 95\% confidence interval (CI) did not include zero (for mean difference) or one (for odds ratio) were estimated. A statistical heterogeneity was evaluated by the Q-statistic, with a $\mathrm{P}$ value less than 0.05 considered significant heterogeneity. If $\mathrm{P}>0.05$, individual study effects were pooled using a fixed effects model using the Mantel-Haenszel method(Mantel and Haenszel, 1959). Otherwise, the pooled OR and P values were calculated by the random-effect model using DerSimonian and Laird method was selected to pool the results, yielding wider CIs (DerSimonian and Laird, 1986; DerSimonian and Kacker, 2007). The relationship between OR and SE (log [OR]) was analyzed using funnel plot to control publication bias. If funnel plots were lack of symmetry, begg's test and egger's test were also calculated using Stata 12.0software (Stata Corp LP, College Station, USA) to further assessed publication bias (Begg and Mazumdar, 1994; Egger et al., 1997). We assessed potential publication bias by using a funnel plot and Egger's test. When the Egger's test was significant $(P>0.05)$, a trim and fill method was used to adjust for publication bias.

\section{Results}

\section{Study inclusion and characteristics}

A total of 56 documents were retrieved. After application of critical search strategies and exclusion criteria, 5 studies with enough data were eligible for this meta-analysis. These publications included: 4 were relevant to XRCC1 rs25487, 2 were XRCC1 rs179978, 3 were XRCC 3 rs861539, 3 were ERCC1 rs11615, and 2 focused on ERCC2 rs13181. The baseline characteristics of the studies were summarized in Table1. All included studies were published from 2007 to 2012, of which 
DNA Repair Gene Polymorphisms and Therapeutic Response in Rectal Cancer

Table 1. Polymorphisms Involved in this Study and the Response Rate in Different Alleles

\begin{tabular}{|c|c|c|c|c|c|c|}
\hline \multirow[t]{2}{*}{ Gene } & \multirow[t]{2}{*}{ NCBI SNP ID } & \multirow[t]{2}{*}{ Polymorphism } & \multirow[t]{2}{*}{ Genotype } & \multicolumn{2}{|c|}{ Tumour regression grade } & \multirow[t]{2}{*}{ References } \\
\hline & & & & TRG1-2 & TRG3-5 & \\
\hline \multirow[t]{2}{*}{$\mathrm{XRCC} 1$} & rs 25487 & $\mathrm{G}>\mathrm{A}$ & GG & 115 & 83 & (Balboa et al.; Cecchin et al.; \\
\hline & & & $\mathrm{GA}+\mathrm{AA}$ & 159 & 154 & Grimminger et al.; Lamas et al.) \\
\hline \multirow[t]{2}{*}{ XRCC1 } & rs1799782 & $\mathrm{C}>\mathrm{T}$ & $\mathrm{CC}$ & 159 & 124 & (Cecchin et al.; Grimminger et al.) \\
\hline & & & $\mathrm{CT}+\mathrm{TT}$ & 16 & 16 & \\
\hline \multirow[t]{2}{*}{$\mathrm{XRCC} 3$} & rs 861539 & $\mathrm{C}>\mathrm{T}$ & $\mathrm{CC}$ & 51 & 59 & (Cecchin et al.; Grimminger et al.; \\
\hline & & & $\mathrm{CT}+\mathrm{TT}$ & 134 & 165 & Hu-Lieskovan et al.) \\
\hline \multirow[t]{2}{*}{ ERCC1 } & rs 11615 & $\mathrm{C}>\mathrm{T}$ & $\mathrm{CC}$ & 25 & 21 & (Balboa et al.; Cecchin et al.; Lamas et al.) \\
\hline & & & $\mathrm{CT}+\mathrm{TT}$ & 169 & 176 & \\
\hline \multirow[t]{2}{*}{ ERCC2 } & rs 13181 & $\mathrm{~A}>\mathrm{C}$ & AA & 65 & 61 & (Balboa et al.; Cecchin et al.) \\
\hline & & & $\mathrm{AA}+\mathrm{AC}$ & 88 & 89 & \\
\hline
\end{tabular}

Table 2. Characteristics of Studies Involved in the Meta-Analysis

\begin{tabular}{|c|c|c|c|c|c|c|c|}
\hline Authors & Sample: & $\begin{array}{l}\text { Ethnicity Sul } \\
\text { (Country) }\end{array}$ & ubjects & $\begin{array}{l}\text { Disease } \\
\text { stage }\end{array}$ & $\begin{array}{l}\text { Genotyping } \\
\text { method }\end{array}$ & Treatment & $\begin{array}{c}\text { Genes and } \\
\text { polymorphism }\end{array}$ \\
\hline Lamas et al., 2012 & blood & $\begin{array}{l}\text { Caucasian } \\
\text { (Spain) }\end{array}$ & 93 & II IIII & SnapShotassay & RCT+surg & $\begin{array}{l}\text { ERCC1rs11615, (Lamas et al.) } \\
\text { XRCC1 rs } 25487\end{array}$ \\
\hline Siwen et al., 2011 & Tissue & $\begin{array}{l}\text { Caucasian } \\
\text { (Germany, Slovenia }\end{array}$ & ia) 130 & II $\sim \mathrm{IV}$ & PCR-RFLP assays & $\mathrm{RCT}+$ surg & $\begin{array}{ll}\text { CCND1rs9344 } & \text { (Hu-Lieskovan } \\
\text { XRCC3rs861539 } & \text { et al.) }\end{array}$ \\
\hline Cecchin et al., 2011 & 1 blood & $\begin{array}{l}\text { Caucasian (Italy) } \\
\text { (Italy) }\end{array}$ & 238 & NR & $\begin{array}{l}\text { Pyrosequencing, } \\
\text { TaqMan } \\
\text { genotyping assay }\end{array}$ & RCT+surg & $\begin{array}{l}\text { ERCC1 rs11615, (Cecchin et al.) } \\
\text { ERCC2(XPD):rs13181 } \\
\text { XRCC1 rs25487, } \\
\text { XRCC1 rs1799782, } \\
\text { XRCC3rs861539 }\end{array}$ \\
\hline Balboa et al., 2010 & blood & $\begin{array}{l}\text { Caucasianx } \\
\text { (Italy) }\end{array}$ & 65 & II $\sim$ III & SNapShot assay & RCT+surg & $\begin{array}{l}\text { ERCC1 rs11615, (Balboa et al.) } \\
\text { ERCC2(XPD):rs13181 } \\
\text { XRCC1 rs25487 }\end{array}$ \\
\hline Peter,et al., 2010 & Tissue & $\begin{array}{l}\text { Caucasian } \\
\text { (Germany) }\end{array}$ & 81 & NR & $\begin{array}{l}\text { TaqMan } \\
\text { genotyping assay }\end{array}$ & RCT+surg & $\begin{array}{l}\text { XRCC1 rs25487, (Grimminger } \\
\text { XRCC1rs1799782, et al.) } \\
\text { XRCC3rs861539 }\end{array}$ \\
\hline
\end{tabular}

RCT: radio-chemotherapy; Surg: surgery; NR: not reported

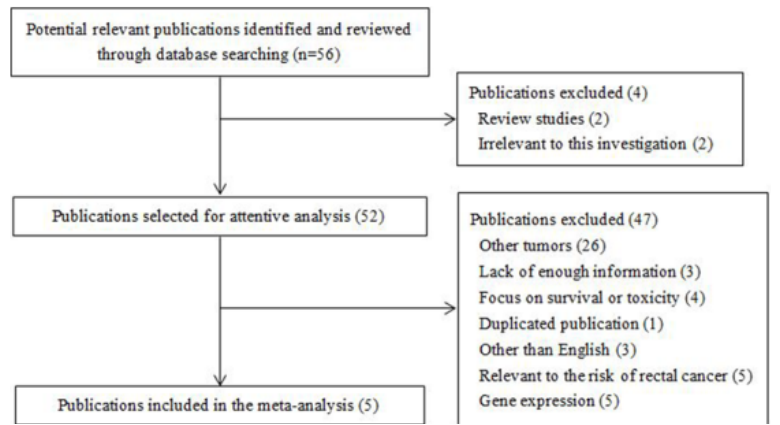

Figure 1. Studies Evaluated Flow Chart of the MetaAnalysis

all papers were performed on Caucasian patients. No evidence of publication bias was detected in the funnel plots of all meta-analysis by visual inspection.

$X R C C 1$ and the response of radiotherapy in rectal cancer

To investigate the association between the XRCC1 RS25487 genotype and the response, four studies were evaluated in this meta-analysis (Figure 1), including a total of 474 patients, the response in the GG and GA+AA genotype group were $48.48 \%$ and $45.65 \%$, respectively. Because there was significant heterogeneity among these studies $\left(p=0.03, \mathrm{I}^{2}=67 \%\right)$, we used a random-effect model to combine these results. The result showed that this polymorphism was not correlated with the response

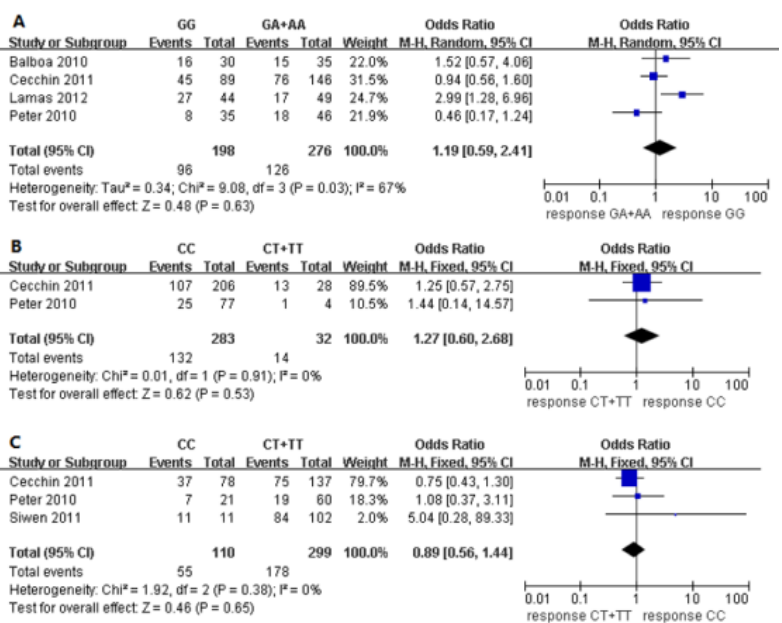

Figure 2. Meta-analysis of Association XRCC1 and XRCC3 Genes Polymorphisms in Predicting Tumor Regression in Rectal Cancer Patients Treated with the Radiotherapy-Based Treatment. A) XRCC1 RS25487, B) XRCC1 RS179978, C) XRCC3 RS861539. The result showed that XRCC1 RS25487, XRCC1 RS179978 and XRCC3 RS861539 were not associated with the response in the radiotherapy-based multimodality treatment of patients with rectal cancer $(\mathrm{p}>0.05)$

(OR=1.19, 95\%CI: 0.59-2.41, $p=0.63$ ) (Figure 2A).

Another XRCC1 polymorphism also evaluated in this meta-analysis was RS1799782 (C>T). The response 
Cheng-Xian Guo et al

\begin{tabular}{|c|c|c|c|c|c|c|c|}
\hline $\begin{array}{l}\text { A } \\
\text { Stuck or Subqroup }\end{array}$ & $\begin{array}{r}\text { CC } \\
\text { Events }\end{array}$ & Total & $\begin{array}{l}\mathrm{CT}+\mathrm{T} \\
\text { Events }\end{array}$ & T & Weight & 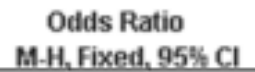 & $\begin{array}{c}\text { Odds Ratio } \\
\text { M.H. Fixed, 95\% CI }\end{array}$ \\
\hline Balboa 2010 & 3 & 8 & 28 & 57 & $23.8 \%$ & $0.62[0.14,2.85]$ & \\
\hline Cecchin 2011 & 15 & 26 & 104 & 207 & $54.2 \%$ & $1.35[0.59,3.08]$ & \\
\hline Lamas 2012 & 7 & 12 & 37 & 81 & $22.0 \%$ & $1.66[0.49,5.69]$ & \\
\hline Total (95\% Cl) & & 46 & & 345 & $100.0 \%$ & $1.25[0.67,2.31]$ & \\
\hline Total events & 25 & & 169 & & & & \\
\hline \multicolumn{7}{|c|}{$\begin{array}{l}\text { Heterogeneity: } \mathrm{Chi}^{2}=1.05, \mathrm{df}=2(P=0.59) ; \mathrm{P}^{2}=0 \% \\
\text { Test for overall effect } Z=0.70(P=0.48)\end{array}$} & $\begin{array}{lccc}0.01 & 0.1 & 1 & 10 \\
\text { response } \mathrm{CT}+\mathrm{TT} & \text { response CC }\end{array}$ \\
\hline $\begin{array}{l}\text { B } \\
\text { Stucty or Subqroup }\end{array}$ & $\begin{array}{c}\text { AA } \\
\text { Events }\end{array}$ & Total & $\begin{array}{l}A C+C \\
\text { Events }\end{array}$ & C & Weight & $\begin{array}{c}\text { Odds Ratio } \\
\text { M.H. Fixed.95\% Cl }\end{array}$ & $\begin{array}{l}\text { Odds Ratio } \\
\text { M.H. Fixed, 95\% Cl }\end{array}$ \\
\hline Balboa 2010 & 11 & 25 & 20 & 40 & $24.3 \%$ & $0.79[0.29,2.14]$ & \\
\hline Cecchin 2011 & 54 & 101 & 68 & 137 & $75.7 \%$ & $1.17[0.70,1.95]$ & \\
\hline Total $(95 \% \mathrm{CI})$ & & 126 & & 177 & $100.0 \%$ & $1.07[0.68,1.70]$ & \\
\hline $\begin{array}{l}\text { Total events } \\
\text { Heter }\end{array}$ & $\begin{array}{r}65 \\
0.7 f=\end{array}$ & & 88 & & & & \\
\hline $\begin{array}{l}\text { Heterogeneity: } \text { Chi }^{2}= \\
\text { Test for overall effect }\end{array}$ & $\begin{array}{l}0.47, d f= \\
Z=0.30(F\end{array}$ & $\begin{array}{l}1(P=C \\
P=0.7\end{array}$ & $\begin{array}{l}0.49) ; P^{2}= \\
6)\end{array}$ & & & & $\begin{array}{ccccc}0.01 & 0.1 & 1 & 10 & 100 \\
\text { response } A C+C C & \text { response } A A\end{array}$ \\
\hline
\end{tabular}

Figure 3. Meta-analysis of Association ERCC1 and ERCC2 Genes Polymorphisms in Predicting Tumor Regression in Rectal Cancer Patients Treated with the Radiotherapy-Based Treatment. A) ERCC1 RS11615, B) ERCC2 RS13181. The result showed that ERCC1 RS11615 and ERCC2 RS13181 were not associated with the response in the radiotherapy-based multimodality treatment of patients with rectal cancer $(\mathrm{p}>0.05)$

in the CC and CT+TT genotype group were $46.64 \%$ and $43.75 \%$, respectively. Because there was heterogeneity among this meta-analysis $\left(p=0.91, \mathrm{I}^{2}=0 \%\right)$, we selected using a fixed -effect model. It found that this SNP was also not associated with the response $(\mathrm{OR}=1.27,95 \% \mathrm{CI}$ : $0.60-2.68, p=0.53$ ) (Figure 2B).

\section{XRCC3 RS861539 and the response of radiotherapy in rectal cancer}

We investigated the association of the XRCC3 RS861539 genetic polymorphism with the response in three trials. The response rates were in the present study $50.00 \%$ and $59.53 \%$ for CC and CT+TT genotype. The fixed-effect model was selected by heterogeneity test $\left(p=0.38, \mathrm{I}^{2}=0 \%\right)$. The result indicated that RS861539 was not associated with the response $(\mathrm{OR}=0.89,95 \% \mathrm{CI}$ : $0.56-1.44, p=0.65$ ) (Figure 2C).

ERCC1 RS11615 and the response of radiotherapy in rectal cancer

Three studies appraised the association between ERCC1 (RS11615) genetic polymorphisms and the response in rectal cancer patients treated with neoadjuvant chemoradiation. 391 subjects (CC genotype and CT+TT genotype carriers) were elected to a meta-analysis on these studies. No heterogeneity $\left(p=0.59, \mathrm{I}^{2}=0 \%\right)$ among these studies was found, and we used a fixed-effects model. Pooling data from these studies revealed $54.35 \%$ and $48.99 \%$ the response in CC genotype and CT+TT genotype group, respectively. No significant associations was detected between ERCC1 (RS11615) and the response $(\mathrm{OR}=1.25,95 \% \mathrm{CI}: 0.67-2.31, p=0.48)$ in the metaanalysis (Figure 3A).

ERCC2 RS13181 and the response of radiotherapy in rectal cancer

ERCC2 RS13181genetic polymorphism was investigated in two trials, including a total of 303 patients.
The response rates in the $\mathrm{AA}$ and $\mathrm{AC}+\mathrm{CC}$ genotype group were $51.59 \%$ and $49.72 \%$, respectively. The fixed-effect model was selected by heterogeneity test $\left(p=0.49, \mathrm{I}^{2}=0 \%\right)$. The result indicated that this genetic polymorphism was no significantly correlated with the response $(\mathrm{OR}=1.07$, 95\% CI: 0.68-1.70, $p=0.76$ ) (Figure 3B).

\section{Discussion}

In this study, we investigated the relationship between DNA repair genes (XRCC1, XRCC1, XRCC3, ERCC1, and ERCC2) common genetic polymorphisms and the response in rectal cancer patients treated with neoadjuvant chemoradiation. The results showed that XRCC1 rs25487, XRCC1 rs179978, XRCC3 rs861539, ERCC1rs11615, and ERCC2 rs13181were not correlated with the response in rectal cancer patients treated with neoadjuvant chemoradiation.

DNA is the main target molecule of ionizing radiation. DNA structure was altered by direct damage of ionizing radiation and indirectly damage of free radicals from ionizing radiation. The level of DNA damage repair capacity is an important factor affecting the radiosensitivity. For DNA damage repair, there are four major signaling pathways known: the base excision repair (BER), the nucleotide excision repair (NER), the mismatch repair (MMR), and the double strand break repair (DSBR) (Yu et al., 1999; Wood et al., 2001). The BER pathway and NER are important for the repair of damaged (Hoeijmakers, 2001). Genetic polymorphisms of genes in DNA repair pathways, will lead to repair activity changes, affecting the efficacy and adverse effects of the radiosensitivity. In the present study, it is interesting that four gene (XRCC1, XRCC3, ERCC1, and ERCC3) genetic polymorphisms.

$\mathrm{X}$-ray repair cross-complementing protein 1 (XRCC1) as one of the most important proteins that plays a key role in the steps of the BER pathway, where it functions 
as a facilitator and coordinator through interaction with DNA polymerases, DNA ligase III and poly ADP - ribose polymerase (PARP)(Masson et al., 1998; Thompson and West, 2000).

Three mainly single nucleotide polymorphisms in XRCC1 were reported. Three polymorphisms are known in the XRCC1 gene: codon 194 (Arg194Trp, $\mathrm{C}>\mathrm{T}$, rs 1799782), 280 (Arg280His, G>A, rs25489), and 399(Arg399Gln, G>A, rs25487)(Shen et al., 1998). These variations may affect the activity of XRCC1 protein. Among them, rs25487 and rs1799782 research in rectal cancer with radiotherapy.

XRCC1 rs25487 at codon 399 was associated with response to platinum-based neoadjuvant chemotherapy in cervical carcinoma patients, since the SNP may have an influence on the expression of XRCC1gene (Cheng et al., 2009). However, Meta-analysis showed that XRCC1 rs25487 not be correlated with the response in rectal cancer patients treated with neoadjuvant chemoradiation. Metaanalysis found that rs 1799782 also is not related to rectal cancer with radiation therapy. Rs25487 and rs 1799782 might not be useful as predictive genetic and molecular markers of rectal tumor response.

$\mathrm{X}$-ray repair cross complementing gene 3 (XRCC3) as the DSB repair-related gene, which encodes a protein that is an important member of the pathway in homologous recombination of homologous recombination (HR). XRCC3 rs861539 (C>T) genetic polymorphism is a non-coding polymorphism in the 5'UTR of the gene. Cecchin, etal found that rs861539 is a protective role toward radiation injury, with decreased tumor response in patients carrying the polymorphism (Cecchin et al., 2010). Peter etal found that no significant associations were detected between rs861539 and the response in rectal cancer patients treated with neoadjuvant chemoradiation (Grimminger et al., 2010). Other studies have found no data are available up to date on the effect of rs861539 on tumor response to radiation (Hu-Lieskovan et al., 2011). Meta-analysis found that rs861539 is not association with rectal cancer with radiation therapy.

Excision repair cross-complementing 1 (ERCC1) is a highly conserved single stranded DNA endonuclease, which is an important part of the NER pathway. Studies have found that ERCC1 (rs11615) gene polymorphisms reveals a significant correlation with response and survival in patients with adenocarcinoma of the esophagus treated with a neoadjuvant radiochemotherapy (Metzger et al., 2012). However, in patients with rectal cancer, we found that rs11615 is no significant correlation with response with a neoadjuvant radiochemotherapy.

Xerodermapigmentosum group D (XPD) gene is also known as excision repair cross-complementing group2 (ERCC2) gene. ERCC2 is an evolutionary conservative DNA helicase, which is an important link of nucleotide excision repair pathways, involved in nucleotide excision repair and bases of transcription. Studies have found that ERCC2 RS13181 can predict clinical outcome in oral squamous cell carcinoma patients and in soft-tissue sarcoma patients treated with postoperative radiotherapy (Mahimkar et al., 2012; Szkandera et al., 2013). However, in patients with rectal cancer, we found that no association between RS13181 and response with a neoadjuvant radiochemotherapy. A reason might be tumor heterogeneity in between soft-tissue sarcoma and rectal cancer.

DNA repair genes polymorphisms might be an important influence to the response with radiotherapy. However, the mate-analysis has not found that DNA repair genes polymorphisms are better predictors. Several reasons might be expected in this type of study. One reason might be the small number of patients. A second reason might be tumor heterogeneity. A third reason might be ethnic variations. A fourth reason might be research method. Most pharmacogenetic studies interesting used candidate gene methods, which focus on a limited number of genotypes with known functions. Therefore, in the future, a number of prospective studies and randomized, controlled pharmacogenetic trials have will be performed in different ethnic groups.

In conclusion, the present study reveals that DNA repair genes common genetic polymorphisms are not significantly correlated with neoadjuvant chemoradiation in rectal cancer patients.

\section{Acknowledgements}

This research is supported by the National Scientific Foundation of China (81301924), Scientific Foundation of Hunan (14JJ7016), and Science and Technology Plan of Changsha (k1403065-31).

\section{References}

Balboa E, Duran G, Lamas MJ, et al (2010). Pharmacogenetic analysis in neoadjuvant chemoradiation for rectal cancer: high incidence of somatic mutations and their relation with response. Pharmacogenomics, 11, 747-61.

Begg CB, Mazumdar M (1994). Operating characteristics of a rank correlation test for publication bias. Biometrics, $\mathbf{5 0}$, 1088-101.

Borchiellini D, Etienne-Grimaldi MC, Thariat J, et al (2012). The impact of pharmacogenetics on radiation therapy outcome in cancer patients. A focus on DNA damage response genes. Cancer Treat Rev, 38, 737-59.

Bouzourene H, Bosman FT, Seelentag W, et al (2002). Importance of tumor regression assessment in predicting the outcome in patients with locally advanced rectal carcinoma who are treated with preoperative radiotherapy. Cancer, 94, 1121-30.

Camma C, Giunta M, Fiorica F, et al (2000). Preoperative radiotherapy for resectable rectal cancer: A meta-analysis. JAMA, 284, 1008-15.

Cecchin E, Agostini M, Pucciarelli S, et al (2010). Tumor response is predicted by patient genetic profile in rectal cancer patients treated with neo-adjuvant chemo-radiotherapy. Pharmacogenomics J, 11, 214-26.

Cheng XD, Lu WG, Ye F, et al (2009). The association of XRCC1 gene single nucleotide polymorphisms with response to neoadjuvant chemotherapy in locally advanced cervical carcinoma. J Exp Clin Cancer Res, 28, 91.

DerSimonian R, Kacker R (2007). Random-effects model for meta-analysis of clinical trials: an update. Contemp Clin Trials, 28, 105-14.

DerSimonian R, Laird N (1986). Meta-analysis in clinical trials. Control Clin Trials, 7, 177-88. 
Egger M, Davey Smith G, Schneider M, et al (1997). Bias in meta-analysis detected by a simple, graphical test. $B M J$, 315, 629-34.

Gordon MA, Gil J, Lu B, et al (2006). Genomic profiling associated with recurrence in patients with rectal cancer treated with chemoradiation. Pharmacogenomics, 7, 67-88.

Grimminger PP, Brabender J, Warnecke-Eberz U, et al (2010). $\mathrm{XRCC1}$ gene polymorphism for prediction of response and prognosis in the multimodality therapy of patients with locally advanced rectal cancer. J Surg Res, 164, 61-6.

Hoeijmakers JH (2001). Genome maintenance mechanisms for preventing cancer. Nature, 411, 366-74.

Hu-Lieskovan S, Vallbohmer D, Zhang W, et al (2011). EGF61 polymorphism predicts complete pathologic response to cetuximab-based chemoradiation independent of KRAS status in locally advanced rectal cancer patients. Clin Cancer Res, 17, 5161-9.

Jemal A, Siegel R, Xu J, et al (2010). Cancer statistics. $C A$ Cancer J Clin, 60, 277-300.

Kapiteijn E, Marijnen CA, Nagtegaal ID, et al (2001). Preoperative radiotherapy combined with total mesorectal excision for resectable rectal cancer. $N$ Engl J Med, 345, 638-46.

Kerns SL, Ostrer H, Rosenstein BS (2014). Radiogenomics: using genetics to identify cancer patients at risk for development of adverse effects following radiotherapy. Cancer Discov, 4, 155-65.

Kockerling F, Reymond MA, Altendorf-Hofmann A, et al (1998). Influence of surgery on metachronous distant metastases and survival in rectal cancer. J Clin Oncol, 16, 324-9.

Lamas MJ, Duran G, Gomez A, et al (2012). X-ray crosscomplementing group 1 and thymidylate synthase polymorphisms might predict response to chemoradiotherapy in rectal cancer patients. Int J Radiat Oncol Biol Phys, 82, 138-44.

Mahimkar MB, Samant TA, Kannan S, et al (2012). Polymorphisms in GSTM1 and XPD genes predict clinical outcome in advanced oral cancer patients treated with postoperative radiotherapy. Mol Carcinog, 51, 94-103.

Mandard AM, Dalibard F, Mandard JC, et al (1994). Pathologic assessment of tumor regression after preoperative chemoradiotherapy of esophageal carcinoma. Clinicopathologic correlations. Cancer, 73, 2680-6.

Mantel N, Haenszel W (1959). Statistical aspects of the analysis of data from retrospective studies of disease. J Natl Cancer Inst, 22, 719-48.

Masson M, Niedergang C, Schreiber V, et al (1998). XRCC1 is specifically associated with poly(ADP-ribose) polymerase and negatively regulates its activity following DNA damage. Mol Cell Biol, 18, 3563-71.

Metzger R, Warnecke-Eberz U, Alakus H, et al (2012). Neoadjuvant radiochemotherapy in adenocarcinoma of the esophagus: ERCC1 gene polymorphisms for prediction of response and prognosis. J Gastrointest Surg, 16, 26-34.

Rajput A, Bullard Dunn K (2007). Surgical management of rectal cancer. Semin Oncol, 34, 241-9.

Read TE, McNevin MS, Gross EK, et al (2001). Neoadjuvant therapy for adenocarcinoma of the rectum: tumor response and acute toxicity. Dis Colon Rectum, 44, 513-22.

Rodel C, Martus P, Papadoupolos T, et al (2005). Prognostic significance of tumor regression after preoperative chemoradiotherapy for rectal cancer. J Clin Oncol, 23, 8688-96.

Roh MS, Colangelo LH, O'Connell MJ, et al (2009). Preoperative multimodality therapy improves disease-free survival in patients with carcinoma of the rectum: NSABP R-03.J Clin Oncol, 27, 5124-30.
Sauer R, Becker H, Hohenberger W, et al (2004). Preoperative versus postoperative chemoradiotherapy for rectal cancer. N Engl J Med, 351, 1731-40.

Shen MR, Jones IM, Mohrenweiser H (1998). Nonconservative amino acid substitution variants exist at polymorphic frequency in DNA repair genes in healthy humans. Cancer Res, 58, 604-8.

Szkandera J, Absenger G, Liegl-Atzwanger B, et al (2013). Common gene variants in RAD51, XRCC2 and XPD are not associated with clinical outcome in soft-tissue sarcoma patients. Cancer Epidemiol, 37, 1003-9.

Terrazzino S, Agostini M, Pucciarelli S, et al (2006). A haplotype of the methylenetetrahydrofolate reductase gene predicts poor tumor response in rectal cancer patients receiving preoperative chemoradiation. Pharmacogenet Genomics, 16, 817-24.

Thompson LH, West MG (2000). XRCC1 keeps DNA from getting stranded. Mutat Res, 459, 1-18.

Vecchio FM, Valentini V, Minsky BD, et al (2005). The relationship of pathologic tumor regression grade (TRG) and outcomes after preoperative therapy in rectal cancer. Int J Radiat Oncol Biol Phys, 62, 752-60.

Wood RD, Mitchell M, Sgouros J, et al (2001). Human DNA repair genes. Science, 291, 1284-9.

Yu Z, Chen J, Ford BN, et al (1999). Human DNA repair systems: an overview. Environ Mol Mutagen, 33, 3-20. 